\title{
The importance of job control for workers with decreased work ability to remain productive at work
}

\author{
Tilja I. van den Berg $\cdot$ Suzan J. Robroek · Jan F. Plat • \\ Marc A. Koopmanschap · Alex Burdorf
}

Received: 19 July 2010 / Accepted: 1 October 2010 / Published online: 16 October 2010

(C) The Author(s) 2010. This article is published with open access at Springerlink.com

\begin{abstract}
Purpose Workers with decreased work ability are at greater risk of reduced productivity at work. We hypothesized that work-related characteristics play an important role in supporting workers to remain productive despite decreased work ability.

Methods The study population consisted of 10,542 workers in 49 different companies in the Netherlands in 20052009. Productivity loss at work was defined on a 10-point scale by asking how much work was actually performed during regular hours on the last regular workday when compared with normal. Independent variables in the logistic regression analysis were individual characteristics, work-related factors, and the work ability index. Additive interactions between work-related factors and decreased work ability were evaluated by the relative excess risk due to interaction (RERI).

Results The odds ratios and 95\% confidence intervals (CI) for the likelihood of productivity loss at work were 2.03 (1.85-2.22), 3.50 (3.10-3.95), and 5.54 (4.37-7.03) for a good, moderate, and poor work ability, compared with an excellent work ability (reference group). Productivity loss at work was associated with lack of job control, poor skill discretion, and high work demands. There was a
\end{abstract}

T. I. van den Berg · S. J. Robroek · A. Burdorf $(\bowtie)$ Department of Public Health,

Erasmus MC University Medical Center,

P. O. Box 2040, 3000 CA Rotterdam, The Netherlands

e-mail: a.burdorf@erasmusmc.nl

J. F. Plat

PreventNed, Enschede, The Netherlands

M. A. Koopmanschap

Department of Health Policy and Management,

Erasmus MC, Rotterdam, The Netherlands significant interaction between decreased work ability and lack of job control $($ RERI $=0.6395 \%$ CI $0.11-1.16)$ with productivity loss at work.

Conclusion The negative effects on work performance of decreased work ability may be partly counterbalanced by increased job control. This suggests that interventions among workers with (chronic) disease that cause a decreased work ability should include enlargement of possibilities to plan and pace their own activities at work.

Keywords Presentism - Productivity loss at work - Work ability $\cdot$ Job control

\section{Introduction}

Various publications have addressed the negative consequences of impaired health, illness, and disease for productivity loss at work. In a systematic review, Schultz et al. showed that different health conditions, such as impaired mental health, allergies, and arthritis, are associated with productivity loss at work (Schultz and Edington 2007). Likewise, individual studies have shown that the prevalence of productivity loss at work had a broad range varying between 7 and 60\% among workers with impaired health (Goetzel et al. 2004; Lötters et al. 2005; Meerding et al. 2005; Geuskens et al. 2008; Martimo et al. 2009). The average productivity loss at work ranged between some 12 and $34 \%$, which accounts for 1.0 to $2.7 \mathrm{~h}$ per day for an $8 \mathrm{~h}$ workday (Goetzel et al. 2004; Lötters et al. 2005; Meerding et al. 2005; Martimo et al. 2009).

A recent study also showed that a decreased ability to cope with work due to the health problems and consequent functional limitations was associated with higher productivity loss at work (Alavinia et al. 2009). Besides health-related 
productivity loss, a reasonable proportion of productivity loss at work will occur due to non-health-related causes, for example machine breakdown, quality problems, and logistic problems (Schultz and Edington 2007; van den Heuvel et al. 2007). Also different work characteristics, such as high physical work demands or high psychosocial work demands, may be related to productivity loss at work. For example, Alavinia et al. (2009) showed that lack of job control, adjusted for the presence of health problems with functional limitations, was associated with productivity loss at work (OR 1.36, 1.14-1.63). Among younger workers with upper extremity symptoms, a combination of high physical load as well as high job strain was also associated with productivity loss at work (Martimo et al. 2009). Therefore, work-related factors, such as high physical and psychosocial work demands, could be important for productivity loss at work, either through their direct influence on productivity or an indirect effect through their influence on workers' health. It is an important question whether the distinguished determinants of productivity loss act completely independent from each other. It may be expected that in certain situations, workers with health problems or decreased work ability have possibilities to prevent productivity loss at work (Geuskens et al. 2008; Alavinia et al. 2009; Böckerman and Laukkanen 2010). We hypothesize that work-related characteristics play an important role in supporting workers to remain productive, despite a decreased work ability.

The research questions were (1) What is the association between decreased work ability and productivity loss at work? (2) What is the association between physical and psychosocial work demands and productivity loss at work? (3) What is the association between decreased work ability and productivity loss at work influenced by high physical or psychosocial workload?

\section{Methods}

\section{Study population}

The study population consisted of 10,542 workers in 49 different Dutch companies in the Netherlands in 20052009. Companies from a whole range of sectors participated, i.e. commercial services $(41 \%)$, non-commercial services $(37 \%)$, industrial manufacturers (18\%), and construction (4\%). These companies had commissioned an occupational health organization to launch a program to investigate the work ability of the workforce and as part of this program a questionnaire survey was conducted on health, work demands, work ability, and productivity at work. Companies participating in this program invited all their workers to participate. The occupational health organization had send an invitation to all eligible workers by regular mail and provided them with an individualized password to fill out the questionnaire on a secured Web site. At the time of enrolment, written informed consent was obtained from all participants.

In the original study population, non-responders accounted for 7,905 subjects (42\%). Some workers did not fill out questions on productivity at work $(0.8 \%)$, work ability index $(1.1 \%)$, or work-related factors $(3.6 \%)$. Complete data on productivity loss at work, work ability, and workrelated factors were present for 10,542 subjects (56\%), which were made available to the Erasmus Productivity Loss at Work database (ELPW database).

\section{Productivity}

The main outcome of this study, productivity loss at work, was collected using the quantity scale of the quantity and quality (QQ) instrument (Brouwer et al. 1999). Respondents were asked to indicate how much work they had actually performed during regular hours on their most recent regular workday relative to a normal workday. The quantity of productivity was measured on a 10-point numerical rating scale with 0 representing "nothing" and 10 representing "normal quantity". The outcome was dichotomized into those with productivity loss at work (score less than 10) and those without (productivity score $=10$ ). The quality of productivity was not measured because the quality and quantity question is highly correlated (Meerding et al. 2005).

\section{Work ability index}

The work ability index (WAI) (Tuomi et al. 1998; Ilmarinen 2009) is a measure for the degree to which a worker, given his health, is physically and mentally able to cope with the demands at work. The WAI consists of an assessment of work ability relative to physical and mental work demands at this moment, diagnosed diseases, and limitations in work due to disease, sick leave over the past 12 months, work ability prognosis within 2 years, and psychological resources recently. The WAI constitutes of seven dimensions, the index being derived as the sum of the ratings on these dimensions. The range of the summative index is 7-49 classifies work ability into poor (7-27), moderate (28-36), good (37-43), or excellent (44-49). Decreased work ability was defined as a score lower than 37 (poor and moderate).

\section{Work-related factors}

The work-related factors in the questionnaire consisted of items on physical and psychosocial demands. Physical load in the current job concerned the regular presence of manual 
materials handling, awkward back postures in which the back is bent or twisted, static work postures, repetitive movements, and bending and/or twisting of the upper body. For all physical loads, a four-point scale was used with rating 'seldom or never', 'now and then', 'often', and 'always' during a normal workday. The answers 'often' and 'always' were classified as high exposure (Elders and Burdorf 2001).

The psychosocial workload was measured according to the demand-control model by Karasek et al. (1981, 1998). The three dimensions job control (5 items), skill discretion (3 items), and work demands (5 items) were assessed using an abbreviated version of the original questionnaire (Cronbach's alpha $=0.76$ ) (Pelfrene et al. 2001). Questions on job control concerned workers' influence on the planning of tasks, ability to interrupt work if necessary, and whether or not they had a say on completion of deadlines. Skill discretion covered creativity, varied work, and required skills and abilities. Work demands related to excessive work, working hard, working fast, insufficient time to complete the work, and conflicting demands. For each question, a four-point scale was used with ratings 'seldom or never', 'now and then', 'often', and 'always' during a normal workday. The sum score was calculated for each dimension separately, and workers with a median sum score or higher were regarded as exposed to the psychosocial risk factor (Alavinia et al. 2009).

\section{Statistical analysis}

Descriptive statistics were used to describe the characteristics of the study population. Since the magnitude of productivity loss was not normally distributed, the dichotomous variable productivity loss at work (yes/no) was used as dependent variable in the logistic regression analysis to explore the association between productivity loss at work and independent variables individual characteristics, work ability, work ability dimensions, psychosocial work demands, and physical workload. The odds ratio (OR) was estimated as measure of association with corresponding 95\% confidence intervals $(95 \% \mathrm{CI})$. In the first step of the analysis, univariate associations were evaluated. Subsequently, all variables in the univariate analyses with $p<0.05$ were investigated in a multivariate analysis using a forward technique with significance level $p<0.05$.

Population attributable fractions (PAFs) were calculated for less than good work ability, using the formula $\mathrm{PAF}=\mathrm{Pe}$ $(\mathrm{OR}-1) /(1+\mathrm{Pe}(\mathrm{OR}-1))$, whereby $\mathrm{Pe}$ is the prevalence in the study population (Hennekens et al. 1987).

We were interested in the potential additive interaction between a decreased work ability and poor working conditions on the presence of productivity loss. Therefore, interactions between work ability and work-related factors were estimated for work-related factors which remained statistically significant at $p<0.05$ in the multivariate model. Interaction was considered to be present when the combined association of both factors (decreased work ability as well as poor working conditions) was larger than the sum of the independent associations of decreased work ability and poor working conditions. Interaction terms were defined by product terms of dichotomized variables, resulting in four exposure categories. Subjects with a good or excellent work ability and good working conditions were defined as reference category. The relative excess risk due to interaction (RERI) was estimated as measure for interaction with confidence levels based on covariances in line with the delta method of Hosmer and Lemeshow (1992), using the following formula: RERI $=$ RR (Decreased WAI and poor working condition) - RR (Decreased WAI and good working condition) $-\mathrm{RR}$ (Good WAI and poor working condition) +1 (Andersson et al. 2005). In order to calculate RERI from a logistic regression analysis, we assumed that the odds ratios could be used as a fair approximation of relative risks. RERI can be interpreted as a measure of departure from additivity adjusted for confounders, in which a RERI of zero means no departure from additivity. The additive interaction is considered statistically significant when zero is outside the $95 \%$ confidence interval (CI). All analyses were carried out with the Statistical Package for Social Sciences version 15.0 for Windows (1999).

\section{Results}

About $44 \%$ of the subjects reported productivity loss at work during the last workday, with an average loss of $11.4 \%$ compared with a regular workday (Table 1). This indicates an average loss of $0.9 \mathrm{~h}$ on an 8 -h workday. The mean age of the study population was about 44 years, ranging from 18 to 68 years. The distribution of excellent, good, moderate, and poor work ability was $32.8,47.4,16.4$, and $3.4 \%$, respectively. Work-related factors were moderate interrelated with Pearson correlations ranging from -0.10 to 0.39 for psychosocial work characteristics, whereas Pearson correlations between physical work factors ranged from -0.11 to 0.52 , and Pearson correlations between psychosocial and physical work factors ranged from 0.03 to 0.26 .

The odds ratios and $95 \%$ confidence intervals (CI) for the likelihood of productivity loss were 2.03 (1.85-2.22), 3.50 (3.10-3.95), and 5.54 (4.37-7.03) for a good, moderate, and poor work ability, compared with an excellent work ability (reference group).

The population attributable fraction for productivity loss at work due to less than good work ability was $10 \%$. Associations between decreased work ability and productivity 
Table 1 Individual characteristics, work-related factors, work ability index, and productivity loss at work among 10,542 workers in the Netherlands

\begin{tabular}{lc}
\hline Variable & Frequency $(\%)$ \\
\hline Age category & \\
18-39 years & $33.5(N=3,529)$ \\
40-49 years & $34.4(N=3,627)$ \\
50-68 years & $32.1(N=3,386)$ \\
Female worker & $42.8(N=4,512)$ \\
Psychosocial work demands & \\
Lack of job control & $59.4(N=6,266)$ \\
Poor skill discretion & $73.5(N=7,747)$ \\
High work demand & $58.7(N=6,189)$ \\
Physical work demands & \\
Manual materials handling & $6.4(N=671)$ \\
Awkward back postures & $13.7(N=1,447)$ \\
Static working postures & $43.8(N=4,621)$ \\
Repetitive movements & $46.2(N=4,873)$ \\
Bending or twisting upper body & $33.3(N=3,510)$ \\
Work ability score & \\
Excellent & $32.8(N=3,454)$ \\
Good & $47.4(N=4,999)$ \\
Moderate & $16.4(N=1,730)$ \\
Poor & $3.4(N=359)$ \\
Productivity loss (score $<10)$ & $44.3(N=4,666)$ \\
\hline &
\end{tabular}

loss were most influenced by the dimensions 'general work ability' (dimension 1), 'work ability in relation to physical and mental demands' (dimension 2), and 'prognosis of work ability' (dimension 6) (Table 2). The four healthrelated dimensions (number of diagnosed diseases, subjective estimation of work impairment due to disease, sickness absence during the past year, and psychological resources) did not remain significant in the multivariate model, when adjusted for other dimensions.

Older workers and women showed inverse associations with productivity loss at work (Table 3 ). The psychosocial factors lack of job control, high workload, and poor skill discretion were associated with productivity loss at work, with odds ratios remaining quite comparable in the multivariate analysis. The physical factors awkward back postures, static working postures, and repetitive movements showed statistically significant associations in the univariate analyses, which did not remain significant in the multivariate analysis. None of the physical work demands had a significant contribution in the multivariate model with ORs varying from 1.01 to 1.03 .

Table 4 shows the joint effects of psychosocial work factors and work ability on productivity loss at work. For all three psychosocial factors and work ability, the joined effect was strongly associated with productivity loss at work than the single effects of both variables. The RERI for job control was $0.63(0.11-1.16)$, for skill discretion 0.24 $(-0.31-0.79)$, and for work demand $-0.07(-0.65-0.51)$. As zero was outside the confidence interval for lack of job control, the interaction between decreased work ability and lack of job control was statistically significant. In other words, we found a statistically significant additive interaction between lack of job control and decreased work ability for the association with productivity loss. RERI can then be interpreted as the proportion of productivity loss at work among those workers with decreased work ability and lack of job control that is attributable to their interaction.

Within workers with a good work ability, the presence of lack of job control was associated with a $23 \%$ increase in likelihood of productivity loss at work. Within workers with a decreased work ability, lack of job control had a $38 \%$ increase in the occurrence of productivity loss at work.

\section{Discussion}

Decreased work ability showed statistical significant associations with productivity loss at work, especially in combination with lack of job control. In other words, job control
Table 2 Univariate and multivariate associations of work ability dimensions and productivity loss at work among 10,542 workers

\begin{tabular}{|c|c|c|c|c|c|}
\hline \multirow[t]{3}{*}{ WAI dimension } & \multirow[t]{3}{*}{ Mean (SD) } & \multicolumn{4}{|c|}{ Productivity loss $(1 / 0)$} \\
\hline & & \multicolumn{2}{|c|}{ Univariate } & \multicolumn{2}{|c|}{ Multivariate } \\
\hline & & OR & $95 \% \mathrm{CI}$ & OR & $95 \% \mathrm{CI}$ \\
\hline General work ability $(0-10)$ & $8.18(1.60)$ & $0.68 *$ & $0.66-0.70$ & $0.73^{*}$ & $0.70-0.76$ \\
\hline $\begin{array}{l}\text { Work ability in relation to physical } \\
\text { and mental demands }(2-10)\end{array}$ & $8.29(1.22)$ & $0.69 *$ & $0.66-0.71$ & $0.87 *$ & $0.83-0.91$ \\
\hline Diagnosed diseases (1-7) & $4.66(1.82)$ & $0.91 *$ & $0.89-0.93$ & - & \\
\hline Impairment due to diseases (1-6) & $5.11(1.31)$ & $0.82 *$ & $0.79-0.84$ & - & \\
\hline Sickness absence (1-5) & $4.19(0.95)$ & $0.80 *$ & $0.77-0.84$ & - & \\
\hline Prognosis work ability $(1,4,7)$ & $6.56(1.27)$ & $0.84 *$ & $0.82-0.87$ & $0.96^{*}$ & $0.93-0.99$ \\
\hline Psychological resources (1-4) & $3.43(0.65)$ & $0.64 *$ & $0.60-0.68$ & - & \\
\hline
\end{tabular}


Table 3 Univariate and multivariate associations of individual characteristics and work-related factors with productivity loss among 10,542 workers

$* p<0.05$

Table 4 Interaction between work ability and work-related factors in the association with productivity loss at work among 10,542 workers

$R E R I$ relative excess risk due to interaction

$* p<0.05$, adjusted for age and $\operatorname{sex}$

\begin{tabular}{|c|c|c|c|c|}
\hline \multirow[b]{2}{*}{ Variable } & \multicolumn{2}{|c|}{ Univariate model } & \multicolumn{2}{|c|}{ Multivariate model } \\
\hline & OR & $95 \% \mathrm{CI}$ & OR & $95 \% \mathrm{CI}$ \\
\hline \multicolumn{5}{|l|}{ Age category } \\
\hline 18-39 years (Ref) & 1.00 & & 1.00 & \\
\hline $40-49$ years & $0.83 *$ & $0.76-0.91$ & $0.83 *$ & $0.75-0.91$ \\
\hline $50-68$ years & $0.81 *$ & $0.74-0.89$ & $0.82 *$ & $0.74-0.90$ \\
\hline Female worker & $0.91 *$ & $0.85-0.99$ & $0.87 *$ & $0.81-0.95$ \\
\hline \multicolumn{5}{|l|}{ Psychosocial work demands } \\
\hline Lack of job control & $1.38 *$ & $1.28-1.50$ & $1.32 *$ & $1.22-1.43$ \\
\hline Poor skill discretion & $1.28 *$ & $1.18-1.40$ & $1.20^{*}$ & $1.10-1.32$ \\
\hline High work demand & $1.30 *$ & $1.20-1.40$ & $1.28 *$ & $1.18-1.39$ \\
\hline \multicolumn{5}{|l|}{ Physical work demands } \\
\hline Manual materials handling & 1.11 & $0.95-1.30$ & - & \\
\hline Awkward back postures & $1.13 *$ & $1.01-1.26$ & - & \\
\hline Static working postures & $1.09 *$ & $1.01-1.18$ & - & \\
\hline Repetitive movements & $1.09 *$ & $1.01-1.17$ & - & \\
\hline Bending or twisting upper body & 0.94 & $0.87-1.02$ & - & \\
\hline
\end{tabular}

\begin{tabular}{lllll}
\hline & OR & $95 \%$ CI & RERI & $95 \%$ CI \\
\hline Model 1: WAI and job control & & & & \\
Good WAI and high job control & 1.00 & & $0.63^{*}$ & $0.11-1.16$ \\
Good WAI and lack of job control & $1.23^{*}$ & $1.13-1.34$ & & \\
Decreased WAI and high job control & $2.25^{*}$ & $1.87-2.70$ & & \\
Decreased WAI and lack of job control & $3.11^{*}$ & $2.75-3.52$ & & -0.31 to 0.79 \\
Model 2: WAI and skill discretion & & & & \\
Good WAI and high skill discretion & 1.00 & & & \\
Good WAI and poor skill discretion & $1.18^{*}$ & $1.07-1.30$ & & \\
Decreased WAI and high skill discretion & $2.51^{*}$ & $2.02-3.14$ & & -0.65 to 0.51 \\
Decreased WAI and poor skill discretion & $2.93^{*}$ & $2.58-3.34$ & & \\
Model 3: WAI and work demand & & & & \\
Good WAI and low work demand & 1.00 & & & \\
Good WAI and high work demand & $1.22^{*}$ & $1.12-1.34$ & & \\
Decreased WAI and low work demand & $2.73^{*}$ & $2.29-3.26$ & & \\
Decreased WAI and high work demand & $2.89^{*}$ & $2.55-3.27$ & & \\
\hline
\end{tabular}

seems to act as a buffer in the association between decreased work ability and productivity loss at work.

Some limitations must be considered in this study. First of all, the cross-sectional design of the study does not permit further explanation of the causal relationship between determinants and productivity loss at work. The results of this study do not indicate whether productivity loss at work was a result of decreased work ability or decreased work ability was a result of lack of productivity. The cross-sectional design also limits insight into the 'lag time' between decreased work ability and productivity loss at work. It could be that recent decreased work ability has a stronger effect on productivity loss at work because a worker with a longer period of decreased work ability could have changed working tasks or found coping techniques to remain productive despite decreased work ability.

Secondly, a subjective measure of productivity loss at work was used. Since objective measures of productivity at work are rarely available or difficult to access, self-reports to estimate the decrease in productivity are more common (Koopmanschap et al. 2005; Burdorf 2007). One study showed significant correlations between self-reported productivity and objective work output $(r=0.48)$ among floor layers (Meerding et al. 2005). Nevertheless, the current 
study was done in a large array of different work settings and only used the quantity question of the QQ method. A measure of productivity loss at work concerning the last workday was used, because a longer time span may be influenced by self-reports. A disadvantage of a time-span of 1 day is that it does not take into account the expected fluctuations in productivity loss within workers across workdays. This unknown daily fluctuation will have contributed to random measurement error and thus attenuated the observed associations. Although participants were informed that all information would be handled completely anonymous, it also cannot be discarded that some information bias might have occurred, for example due to reluctance among participants to report reduced productivity at work due to fear of negative consequences.

Thirdly, a low response may also be associated with the presence of productivity loss at work. The response for the productivity item varied from 9 to $96 \%$ across companies. Within each company, it may be possible that workers with productivity loss at work have had less interest in participating in the study. The response level was lower in large companies, in commercial services companies, and among blue-collar workers. However, using a cutoff of $80 \%$ response, no significant differences were found in productivity loss at work between companies with high and low response levels, and response level was also not statistically significant when included in the univariate analyses. Therefore, we think that this source of selection bias will not have influenced the results to a major extent.

Finally, we used the RERI as a measure for interactivity on an additive scale. Therefore, we needed to make the assumption that the joint mechanism between lack of job control and decreased work ability follows an additive pattern and assumes that the odds ratios could be used as a fair approximation of relative risks. One of the disadvantages of this method is that it handles only two covariates, otherwise data in each stratum become too sparse.

Under the assumption of a causal relation between decreased work ability and productivity loss at work, we estimated that only $10 \%$ of productivity loss at work was attributable to a decreased work ability. A previous study also reported that $7 \%$ of productivity loss at work was attributable to impaired health and that health impairments were strongly related to productivity loss at work than the number of diagnosed diseases (Alavinia et al. 2009). This is not very surprising, given the fact that the measure of productivity loss at work used in this study estimates all productivity loss at work, not necessarily health related. There are various reasons for lost productivity which may have nothing to do with health including machine breakdown, personal issues, and organisational problems. However, when workers are asked if their productivity loss is due to impaired health, the percentage of health-related productiv- ity loss at work will be much higher. For instance, in a group of workers with musculoskeletal complaints, $75 \%$ of the subjects reported that productivity loss was due to their musculoskeletal disorders (Lötters et al. 2005).

Associations between decreased work ability and productivity loss at work were most influenced by the dimensions 'general work ability', 'work ability in relation to physical and mental demands', and 'self-reported prognosis of work ability'. These dimensions primarily reflect individual capacities to cope with work demands. Several aspects may explain the importance of these 'capacity dimensions'. First of all, there are substantial differences in recall time among the seven work ability dimensions. For example, the first two dimensions are concerned with the current situation; dimension five relates to the past 12 months, dimension six alludes to the coming 2 years, whereas dimension seven refers to the current situation. Second, work ability dimensions are highly interrelated (Pearson correlations ranged from 0.13 to 0.57 ) and as a consequence only the dimensions with the strongest influence will be retained in the multivariate analysis.

The first two dimensions of the work ability index seem to reflect to some extent a productivity measure.

Our finding that productivity loss at work was associated with poor work factors corroborates previous studies (Aronsson and Gustafsson 2005; Alavinia et al. 2009; Martimo et al. 2009). A positive association between high workload and productivity loss at work was for example also reported in a Finnish study showing that regular overtime increases sickness presentism (Böckerman and Laukkanen 2010). When work tasks are perceived as highly demanding, a worker may experience problems complying with the work demands and hence perceive his productivity as below par. Perceived health limitations will only further increase the perception that required work output levels are not achieved and therefore result in increased productivity loss at work.

In agreement with Alavinia et al. (2009) and Martimo et al. (2009), high physical work demands seemed less important for productivity loss at work than psychosocial work characteristics. Different explanations could be a reason for this finding. First, job control and the related possibility to adjust work activities could act as a buffer in highly physical demanding professions in such a way that a worker with musculoskeletal complaints can eliminate the high physical demanding task for that specific day or period. Alternatively, questions concerning psychosocial work factors could be more individual oriented, whereas physical work factors may reflect more objective working conditions. The finding could also be due to the cross-sectional design of the study, whereby it is not clear whether the lack of association between high physical work demands and productivity loss at work is due to a healthy worker effect. 
The association between decreased work ability and productivity loss at work differed for the absence or presence of poor psychosocial work factors. Especially, job control seems an important factor to remain productive when experiencing decreased work ability. Johansson and Lundberg (2004) have proposed in their model 'illness flexibility' that employees with a high degree of control of their work tasks or adjustment latitude are more likely to go to work because they can modify their work tasks in such a way as to be able to carry on despite impaired health. A comparable mechanism for productivity loss at work could be envisaged in the sense of having opportunities to change tasks in such a way that they can still be performed despite health impairments. Social support was not measured in the current study, but it was shown that among workers with impaired health due to early inflammatory joint conditions, low support from colleagues predicted a reduced productivity at work (Geuskens et al. 2008). Likewise, effort-reward imbalance and job dissatisfaction were not measured, but strong associations were found between both psychosocial factors with productivity loss at work in a population of office workers reporting work-related neck/shoulder or hand/arm symptoms during the past 3 months (van den Heuvel et al. 2007). The importance of job control in continuing work or remaining active appears also from literature on return to work and sickness absence for specific diagnostic groups (Duijts et al. 2007; Werner and Cote 2009).

In conclusion, this study confirmed that workers whose work ability was decreased reported more productivity loss at work. Job control buffered the loss of productivity at work among workers with decreased work ability. These results confirm that the relation between impaired health and decreased work output depends on autonomy of the worker. Hence, levels of productivity loss within specific diagnostic disease groups will not be equal for all workers. Job control can be increased by giving workers the opportunities to decide themselves for example on their working goal, working method, or working hours, taking into account existing quality norms.

Conflict of interest The authors declare that they have no conflict of interest.

Open Access This article is distributed under the terms of the Creative Commons Attribution Noncommercial License which permits any noncommercial use, distribution, and reproduction in any medium, provided the original author(s) and source are credited.

\section{References}

Alavinia SM, Molenaar D, Burdorf A (2009) Productivity loss in the workforce: associations with health, work demands, and individual characteristics. Am J Ind Med 52:49-56
Andersson T, Alfredsson L, Kallberg H, Zdravkovic S, Ahlbom A (2005) Calculating measures of biological interaction. Eur J Epidemiol 20:575-579

Aronsson G, Gustafsson K (2005) Sickness presenteeism: prevalence, attendance-pressure factors, and an outline of a model for research. J Occup Environ Med 47(9):958-966

Böckerman P, Laukkanen E (2010) What makes you work while you are sick? Evidence from a survey of workers. Eur J Public Health 20:43-46

Brouwer WB, Koopmanschap MA, Rutten FF (1999) Productivity losses without absence: measurement validation and empirical evidence. Health Policy 48:13-27

Burdorf A (2007) Economic evaluation in occupational health-its goals, challenges, and opportunities. Scand J Work Environ Health 33:161-164

Duijts SF, Kant I, Swaen GM, van den Brandt PA, Zeegers MP (2007) A meta-analysis of observational studies identifies predictors of sickness absence. J Clin Epidemiol 60:1105-1115

Elders LA, Burdorf A (2001) Interrelations of risk factors and low back pain in scaffolders. Occup Environ Med 58:597-603

Geuskens GA, Hazes JM, Barendregt PJ, Burdorf A (2008) Predictors of sick leave and reduced productivity at work among persons with early inflammatory joint conditions. Scand J Work Environ Health 34:420-429

Goetzel RZ, Long SR, Ozminkowski RJ, Hawkins K, Wang S, Lynch W (2004) Health, absence, disability, and presenteeism cost estimates of certain physical and mental health conditions affecting US employers. J Occup Environ Med 46:398-412

Hennekens CB, Buring B, Mayrent S (1987) Epidemiology in medicine. Lippincott Williams \& Wilkins, Boston

Hosmer DW, Lemeshow S (1992) Confidence interval estimation of interaction. Epidemiology 3(5):452-456

Ilmarinen J (2009) Work ability - a comprehensive concept for occupational health research and prevention. Scand J Work Environ Health 35:1-5

Johansson G, Lundberg I (2004) Adjustment latitude and attendance requirements as determinants of sickness absence or attendance. Empirical tests of the illness flexibility model. Soc Sci Med 58:1857-1868

Karasek R, Baker D, Marxer F, Ahlbom A, Theorell T (1981) Job decision latitude, job demands, and cardiovascular disease: a prospective study of Swedish men. Am J Public Health 71:694-705

Karasek R, Brisson C, Kawakami N, Houtman I, Bongers P, Amick B (1998) The Job Content Questionnaire (JCQ): an instrument for internationally comparative assessments of psychosocial job characteristics. J Occup Health Psychol 3:322-355

Koopmanschap M, Burdorf A, Jacob K, Meerding WJ, Brouwer W, Severens H (2005) Measuring productivity changes in economic evaluation: setting the research agenda. Pharmacoeconomics 23:47-54

Lötters F, Meerding WJ, Burdorf A (2005) Reduced productivity after sickness absence due to musculoskeletal disorders and its relation to health outcomes. Scand J Work Environ Health 31:367-374

Martimo KP, Shiri R, Miranda H, Ketola R, Varonen H, Viikari-Juntura E (2009) Self-reported productivity loss among workers with upper extremity disorders. Scand J Work Environ Health 35:301-308

Meerding WJ, IJzelenberg W, Koopmanschap MA, Severens JL, Burdorf A (2005) Health problems lead to considerable productivity loss at work among workers with high physical load jobs. J Clin Epidemiol 58:517-523

Pelfrene E, Vlerick P, Mak R, de Smet P, Kornitzer M, de Backer G (2001) Scale reliability and validity of Karasek 'Job Demandcontrol-support' model in Belstress. Work Stress 15:297-331

Schultz AB, Edington DW (2007) Employee health and presenteeism: a systematic review. J Occup Rehabil 17:547-579 
Statistical package for the social sciences (SPSS) (1999) 15.0 ed. SPSS, Chicago, IL

Tuomi K, Ilmarinen J, Jahkola A, Katajarinne L, Tulkki A (1998) Work ability index. Finnish Institute of Occupational Health, Helsinki

van den Heuvel SG, IJmker S, Blatter BM, de Korte EM (2007) Loss of productivity due to neck/shoulder symptoms and hand/arm symptoms: results from the PROMO-study. J Occup Rehabil 17:370-382

Werner EL, Cote P (2009) Low back pain and determinants of sickness absence. Eur J Gen Pract 15:74-79 